\title{
Impact of different thickness of the smooth heated surface on flow boiling heat transfer
}

\author{
Kinga Strąk $^{*}$, Magdalena Piasecka \\ Faculty of Mechatronics and Mechanical Engineering \\ Kielce University of Technology, Al. 1000-lecia P.P. 7, 25-314 Kielce, Poland
}

\begin{abstract}
This paper presents a comparison of the performance of three smooth heated surfaces with different thicknesses. Analysis was carried out on an experimental setup for flow boiling heat transfer. The most important element of the setup was the test section with a rectangular minichannel, $1.7 \mathrm{~mm}$ deep, $16 \mathrm{~mm}$ wide and $180 \mathrm{~mm}$ long, oriented vertically. The heated element for the FC-72 Fluorinert flowing in the minichannel was designated as a Haynes-230 alloy plate $(0.10 \mathrm{~mm}$ and $0.45 \mathrm{~mm}$ thick) or a Hastelloy X alloy plate $(0.65 \mathrm{~mm}$ thick). Infrared thermography was used to measure the temperature of the outer plate surface. The local values of the heat transfer coefficient for stationary state conditions were calculated using a simple one-dimensional method. The experimental results were presented as the relationship between the heat transfer coefficients in the subcooled boiling region and the distance along the minichannel length and boiling curves. The highest local heat transfer coefficients were recorded for the surface of $0.10 \mathrm{~mm}$ thick heated plate at the outlet and $0.45 \mathrm{~mm}$ thick plate at the minichannel inlet. All boiling curves were typical in shape.
\end{abstract}

\section{Introduction}

The micro and macro-scale devices such as compact heat exchangers, cooling devices, high-powered lasers, and micro-electronics manufacturing systems use flow boiling with phase change on enhanced surfaces to provide the highest possible efficiency of heat transfer. Compared to single-phase flow, larger amounts of thermal energy can be removed when micro- and miniscale channels are used in flow boiling. The flow along minichannels varies considerably from that along macrochannels [1-2].

The first classification of small channels, proposed by Shah and based on the hydraulic diameter, divides them into two groups [3]:

- conventional channels: $d_{h}>6 \mathrm{~mm}$,

- minichannels: $d_{h}<6 \mathrm{~mm}$.

Based on the same criterion, hydraulic diameter $\left(d_{h}\right)$, Kandlikar and Grande introduce new groups [4]:

- conventional channels $-d_{h}>3 \mathrm{~mm}$

- minichannels - $3 \mathrm{~mm} \geq d_{h}>200 \mu \mathrm{m}$

- microchannels - $200 \mu \mathrm{m} \geq d_{h}>10 \mu \mathrm{m}$

- transitional channels- $10 \mu \mathrm{m} \geq d_{h}>0.1 \mu \mathrm{m}$

- transitional microchannels $-10 \mu \mathrm{m} \geq d_{h}>1 \mu \mathrm{m}$

- transitional nanochannels - $1 \mu \mathrm{m} \geq d_{h}>0.1 \mu \mathrm{m}$

- molecular nanochannels - $0.1 \mu \mathrm{m} \geq d_{h}$.

Kew and Cornwell [5] suggest basing the division on the confinement number, $\mathrm{Co}$ :
- microchannels, for $C o<0.5$,

- macrochannels, for $\mathrm{Co}>0.5$.

The Kielce University of Technology has conducted a series of studies devoted to flow boiling heat transfer with refrigerants flowing along minichannels with enhanced heated plates [6-12] at different minichannel orientations [10-12]. The use of enhanced surfaces produced in thermal processes is known to intensify the heat transfer process as shown in [13-15]). Such surfaces are applied also in pool boiling heat transfer [8, 16-20]. Studies on heat transfer in confined spaces as face seals were described in [21-23].

\section{Experiment}

\subsection{Experimental stand}

The study was carried out for a flow boiling process by using the experimental setup shown in Fig. 1. The major part of the setup was the test section with a minichannel, described in detail in $[7,12,24]$

Temperature changes on one side of the plate were measured with an E60 FLIR infrared camera (2) of accuracy: $\pm 1{ }^{\circ} \mathrm{C}$ or $\pm 1 \%$, temperature range: $0 \div 120^{\circ} \mathrm{C}$ [25]. To obtain emissivity of 0.83 [24], the plate surface was coated with black paint. Narrow micanite panels placed on both sides of the plate prevented its deformation. The other side of the plate, in contact with the fluid, was observed through a glass panel. K-type

*Corresponding author:kzietala@tu.kielce.pl 
thermocouples and pressure sensors (8) were installed at the inlet and outlet of the minichannel.

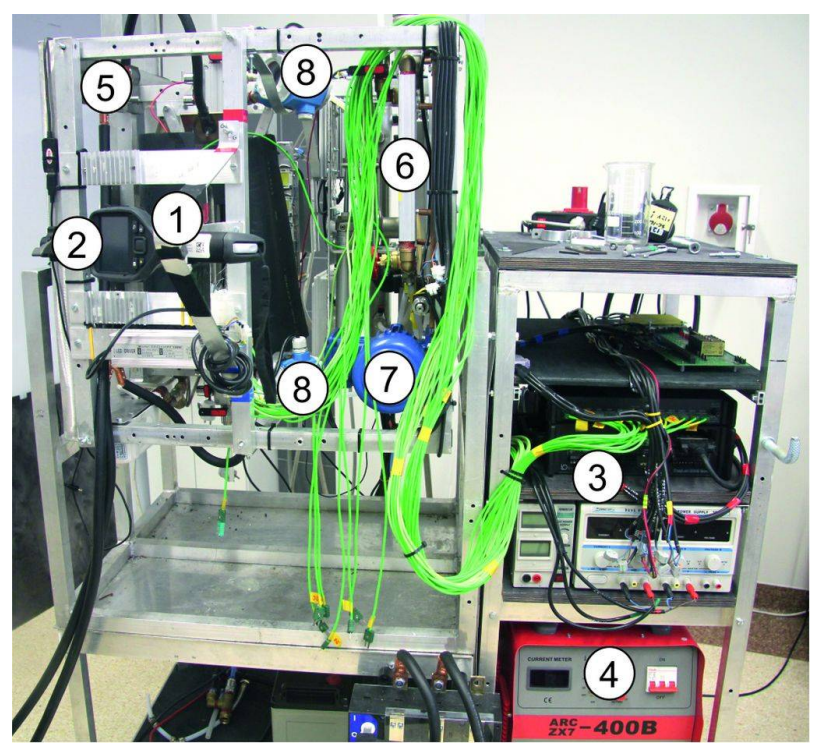

Fig. 1. The image of the main systems of the experimental setup, 1-test section; 2-infrared camera, 3-data acquisition station, 4-inverter welder, 5-shunt, 6-mass flowmeter, 7- gear pump, 8- pressure sensor.

\subsection{Test section and heated plates}

The test section with a rectangular, vertically oriented, $1.7 \mathrm{~mm}$ deep, $16 \mathrm{~mm}$ wide and $180 \mathrm{~mm}$ long minichannel was the most important element of the experimental setup. Figure 2 shows the photograph of the test section. The channel depth is provided by Teflon plate of adequate thickness (2). One of the three smooth surfaces below acted as the heating element (7) for FC-72 flowing in the minichannel:

- Hastelloy X alloy plate, about $0.65 \mathrm{~mm}$ thick,

- Haynes-230 alloy plate, about $0.10 \mathrm{~mm}$ thick,

- Haynes-230 alloy plate, about $0.45 \mathrm{~mm}$ thick.

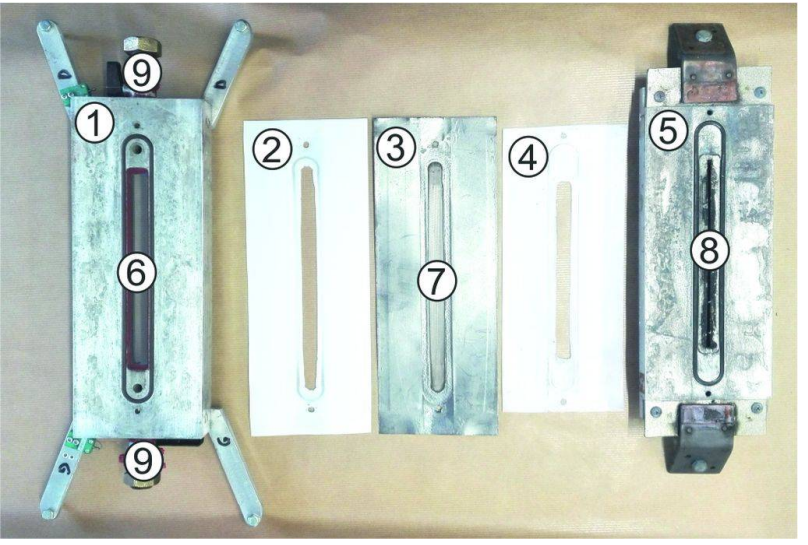

Fig. 2. The image of the test section with the minichannel: 1-front cover, 2, 4-Teflon plate, 3-graphite plate, 5-channel body, 6- glass panel, 7-heated plate, 8-micanite plate, 9-thermocouple.
All the heated plates were manufactured by Haynes Int. Inc. (USA) and chosen for their electrical resistivity, assuming minor resistivity changes with temperature. The Hastelloy X and Haynes-230 alloy plates are made mainly of Ni-Cr-Fe-Mo and Ni-Cr-W-Mo alloys, respectively. In addition to excellent high-temperature strength and oxidation resistance, the alloys exhibit superior long-term stability and fabricability [7, 26].

Figures 3-5 refer to the three types of smooth heated surfaces, $0.10 \mathrm{~mm}, 0.45 \mathrm{~mm}$ and $0.65 \mathrm{~mm}$ thick, respectively, showing the topography of a fragment of the melts (a), 3D topography (b) and a profilogram of a fragment of the single path surface (c).

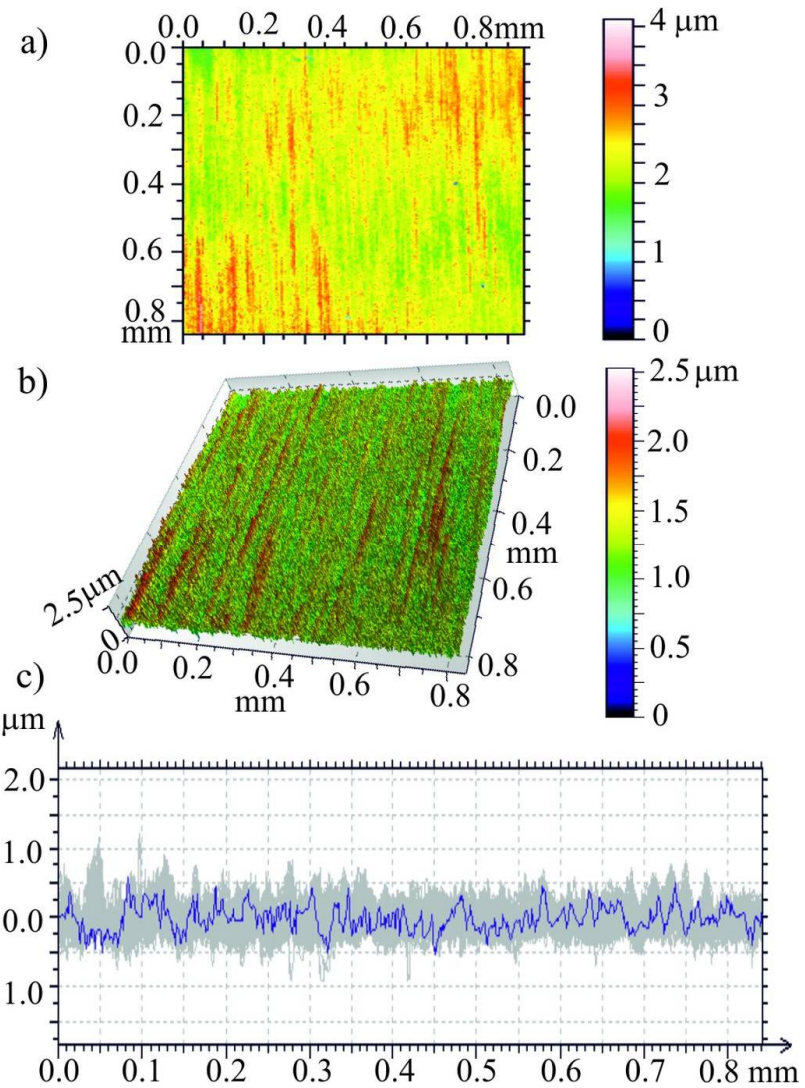

Fig. 3. Fragment of the plate's smooth surface $0.10 \mathrm{~mm}$ thick: a) topography of a fragment of the melts, b) 3D topography, c) roughness profile.

Table 1 compiles main roughness parameters of the surfaces, measured using the optical profilometer Talysurf CCI to ISO 25178-2:2012 manufactured by Taylor Hobson.

Table 1. Main roughness parameters.

\begin{tabular}{|c|c|c|c|}
\hline Parameter of & \multicolumn{3}{|c|}{ Smooth surface thickness: } \\
\cline { 2 - 4 } the surfaces & $0.10 \mathrm{~mm}$ & $0.45 \mathrm{~mm}$ & $0.65 \mathrm{~mm}$ \\
\hline$R a$ & 0.1432 & 0.1752 & 0.1327 \\
\hline$S a$ & 0.1491 & 0.3455 & 0.1444 \\
\hline
\end{tabular}

$R a$ - arithmetic mean deviation of the roughness profile, $\mu \mathrm{m}$ $S a$-arithmetic mean height, $\mu \mathrm{m}$. 


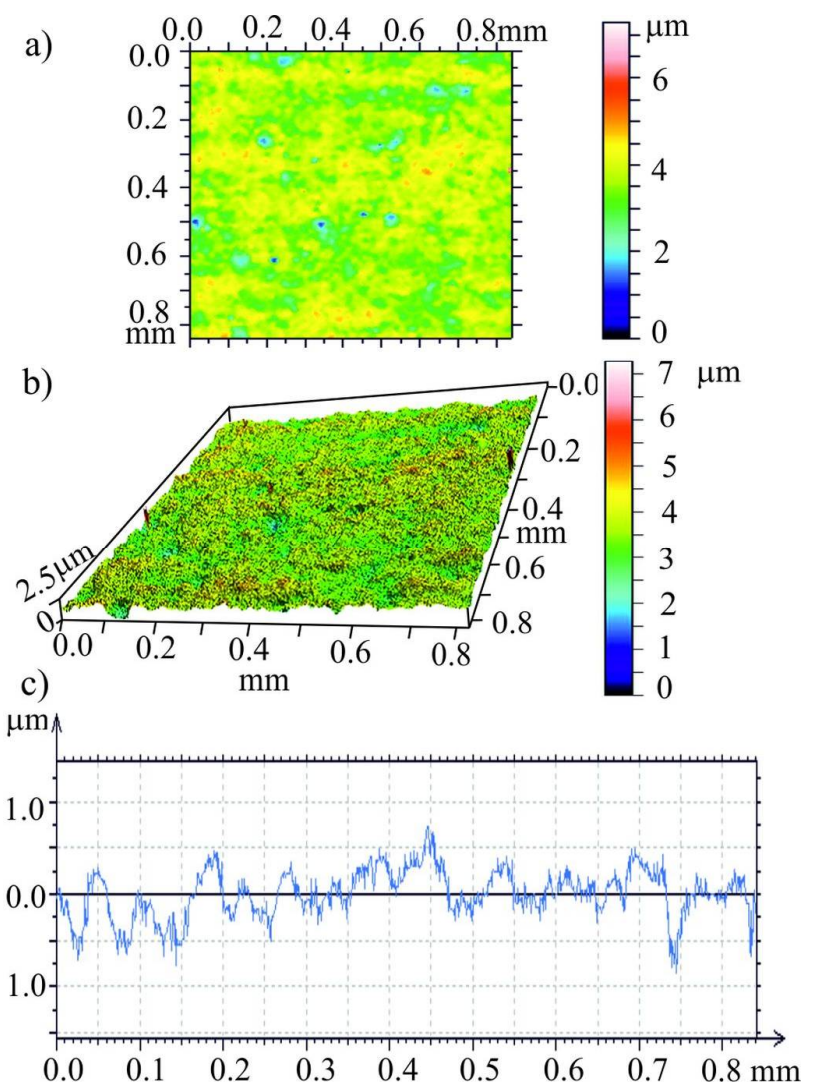

Fig. 4. Fragment of the plate's smooth surface $0.45 \mathrm{~mm}$ thick: a) topography of a fragment of the melts, b) 3D topography, c) roughness profile.

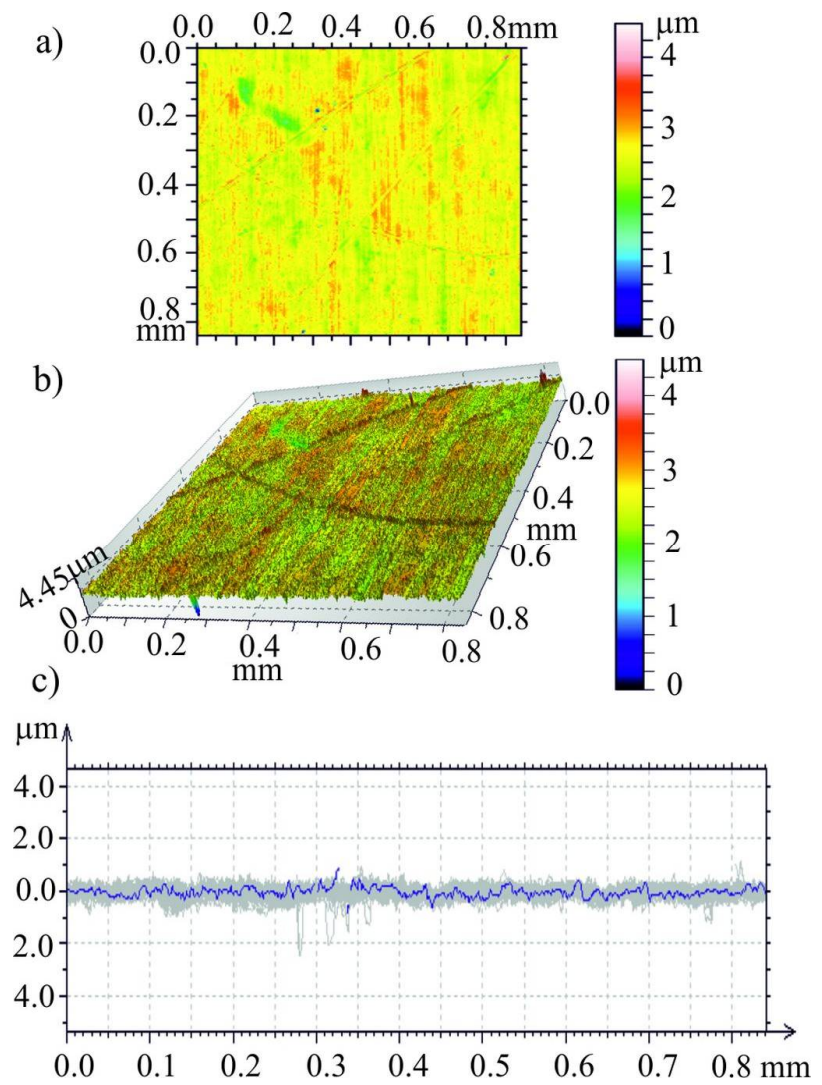

Fig. 5. Fragment of the plate's smooth surface $0.65 \mathrm{~mm}$ thick: a) topography of a fragment of the melts, b) 3D topography, c) roughness profile.
The study of roughness parameters was conducted at the Geometric Computer Measurement Laboratory at the Kielce University of Technology. The profilometer enables non-contact measurement and analysis of the geometric structure of the tested surface [7].

The arithmetic mean deviation of the roughness profile for various surface thicknesses was similar. The values ranged from $0.13 \mu \mathrm{m}$ to $0.18 \mu \mathrm{m}$. The arithmetic mean height for $0.10 \mathrm{~mm}$ and $0.65 \mathrm{~mm}$ surface thicknesses was similar, with $S a$ twice as large for the surface $0.45 \mathrm{~mm}$ thick.

\section{Experiment}

During the experimental series, electric power supplied to the heated plate was gradually increased, as was the heat flux transferred to the fluid in the minichannel, thus initiating nucleate boiling and enhancing heat transfer. The first region after the boiling onset was the subcooled boiling region - the liquid became superheated only in the vicinity of the heated surface; it was highly subcooled in the core of the flow.

The experimental parameters of tested series are presented in Table 2.

Table 2. Experimental parameters of tested series.

\begin{tabular}{|c|c|c|c|c|}
\hline $\begin{array}{c}\text { Thickness } \\
\text { of the } \\
\text { heated } \\
\text { plate } \\
\delta_{P}(\mathrm{~mm})\end{array}$ & $\begin{array}{c}\text { Heat flux } \\
\text { density } \\
q_{w} \\
\left(\mathrm{~kW} \cdot \mathrm{m}^{-2}\right)\end{array}$ & $\begin{array}{c}\text { Mass flux } \\
G \\
\left(\mathrm{~kg} \cdot \mathrm{m}^{-2} \mathrm{~s}^{-1}\right)\end{array}$ & $\begin{array}{c}\text { Inlet } \\
\text { pressure } \\
p_{\text {in }} \\
(\mathrm{kPa})\end{array}$ & $\begin{array}{c}\text { Inlet } \\
\text { liquid } \\
\text { sub- } \\
\text { cooling } \\
\Delta T_{\text {sub }} \\
(\mathrm{K})\end{array}$ \\
\hline \multirow{2}{*}{0.10} & 26 & \multirow{2}{*}{243} & \multirow{2}{*}{198} & \multirow{2}{*}{55} \\
\hline & 40 & & & \\
\hline \multirow{2}{*}{0.45} & 26 & \multirow{2}{*}{423} & \multirow{2}{*}{102} & \multirow{2}{*}{39} \\
\hline & 40 & & & \\
\hline \multirow{2}{*}{0.65} & 26 & \multirow{2}{*}{421} & \multirow{2}{*}{106} & \multirow{2}{*}{38} \\
\hline & 40 & & & \\
\hline
\end{tabular}

\section{Calculations}

The authors of $[6,11,12,24,27-30]$ present various methods of determining the local heat transfer coefficient in the two-dimensional approaches employing Trefftz or Beck methods obtained from solving the inverse problem. In this article, the onedimensional approach is used, taking into account the heat flow direction, which is perpendicular to the direction of the fluid flow in the minichannel.

Local heat transfer coefficients were determined using the one-dimensional method, described also in $[7,24,31]$. In the subcooled boiling region local coefficients are determined from the following equation:

$$
\alpha(x)=q_{w} /\left(T_{P}(x, \delta)-T_{f}(x)-q_{w} \cdot \frac{\delta_{P}}{\lambda_{P}}\right)
$$

$x$ - distance from the minichannel inlet along the direction of the flow, $q_{w}$ - density of the heat flux transferred from the heated plate to the fluid, $T_{p}(x)$ - plate 
temperature, measured by using infrared camera, $T_{f}(x)$ - fluid temperature calculated from the assumption of the linear distribution of the fluid temperature along the minichannel, $\lambda_{P}$ - thermal conductivity of the heated plate, $\delta_{P}$ - thickness of the heated plate.

\section{Results and discussion}

The experiments were recorded for the adopted heat flux supplied to the heated plate under similar stable thermal and flow conditions. The experimental results pertain to the steady state (stationary condition). The analysis includes the data from the experiments performed for three thicknesses of the heated plate: $0.10 \mathrm{~mm}, 0.45 \mathrm{~mm}$ and $0.65 \mathrm{~mm}$. The results are presented graphically as the heat transfer coefficient versus the distance from the minichannel inlet at the the subcooled boiling region for two heat fluxes: $26 \mathrm{~kW} \cdot \mathrm{m}^{-2}$ and $40 \mathrm{~kW} \cdot \mathrm{m}^{-2}$, see Figs. 6 and 7, respectively.

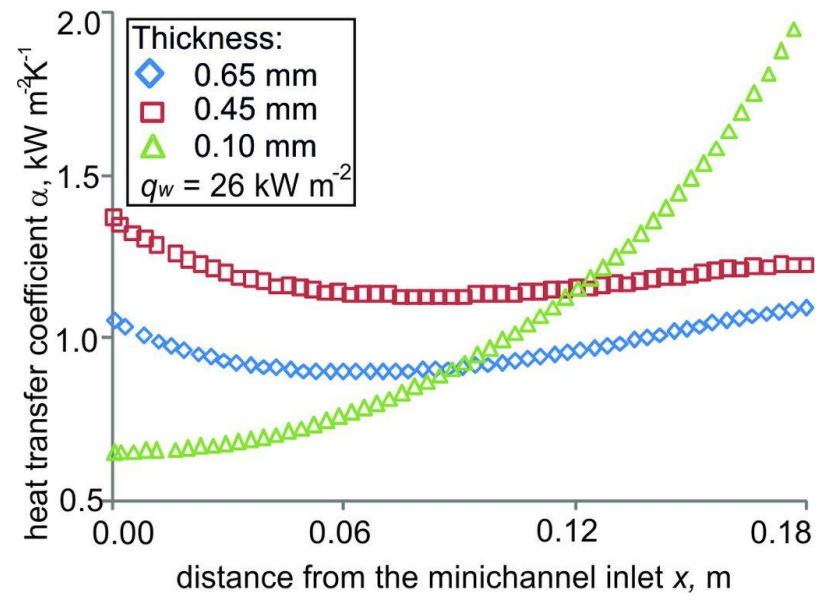

Fig. 6. Heat transfer coefficient vs. distance from the minichannel length obtained for the subcooled boiling region for three tested thicknesses of the heated plate, $q_{w}=26 \mathrm{~kW} \cdot \mathrm{m}^{-2}$.

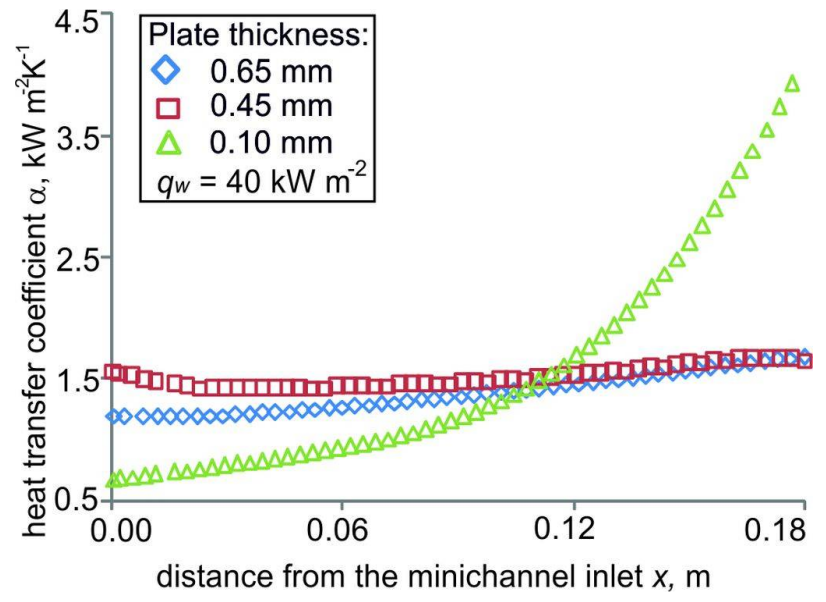

Fig. 7. Heat transfer coefficient vs. distance from the minichannel length obtained for the subcooled boiling region for three tested thicknesses of the heated plate, $q_{w}=40 \mathrm{~kW} \cdot \mathrm{m}^{-2}$.

In the subcooled boiling region (Figs. 6-7), heat transfer coefficients were relatively low in comparison to those at the saturated boiling region [10-12, 27, 29]. The local heat transfer coefficient values increased with the distance from the minichannel inlet to the outlet and achieved maximum of about $4 \mathrm{~kW} \cdot \mathrm{m}^{-2} \cdot \mathrm{K}^{-1}$ for $0.10 \mathrm{~mm}$ thickness of the surface at the $40 \mathrm{~kW} \cdot \mathrm{m}^{-2}$ heat flux (Fig. 7). The highest local heat transfer coefficients were recorded for the surface of $0.10 \mathrm{~mm}$ thick heated plate (from $0.12 \mathrm{~m}$ to $0.18 \mathrm{~m}$ distance from the minichannel inlet) and $0.45 \mathrm{~mm}$ thick plate (from $0 \mathrm{~m}$ to $0.12 \mathrm{~m}$ distance from the minichannel inlet) at all heat fluxes analysed. The surfaces of $0.65 \mathrm{~mm}$ (from $0.12 \mathrm{~m}$ to $0.18 \mathrm{~m}$ distance from the minichannel inlet) and $0.10 \mathrm{~mm}$ (from $0 \mathrm{~m}$ to $0.09 \mathrm{~m}$ distance from the minichannel inlet) thick plates provided the lowest coefficients.

To determine the effect of the heated plate thickness on the value of the heat transfer coefficient, the following quantities were calculated:

1. the value of heat transfer through the heated plate

$$
z(x)=\alpha(x)-q_{w} /\left(T_{P}(x, \delta)-T_{f}(x)\right)
$$

2. the value of heat transfer coefficient from eq. (1) for each heated plate thickness under analysis,

3. the percentage value of heat transfer through the heated plate for various thicknesses of the plate, according to the following relation

$$
y=z / \alpha(x) \cdot 100 \%
$$

Results of calculations are presented in Table 3.

Table 3. Effect of the heated plate thickness on the heat transfer coefficient.

\begin{tabular}{|c|c|c|c|}
\hline & \multicolumn{3}{|c|}{$\begin{array}{c}\text { Percentage value of heat transfer through the } \\
\text { heated plate, } y(\%)\end{array}$} \\
\hline $\begin{array}{c}\text { Heat flux } \\
\text { density, } \\
q_{w}\left(\mathrm{~kW} \cdot \mathrm{m}^{-2}\right)\end{array}$ & 0.10 & 0.45 & 0.65 \\
\cline { 2 - 4 } & 1.2 & 6.4 & 7.6 \\
\hline 26 & 1.8 & 8.2 & 10.8 \\
\hline 40 & \multicolumn{2}{|c|}{ Smooth surface thickness $(\mathrm{mm})$} \\
\hline
\end{tabular}

As the thickness of the plate and the heat flux increased, the percentage of heat transfer through the surface of the plate increased. The smallest percentage was observed for the thinnest plate and the lowest heat flux, while the largest was for the thickest plate and the highest heat flux. The results meet the expectations resulting from the description of heat transfer according to the Fourier law.

The boiling curves shown in Fig. 8 were constructed for the three plate thickness. The curves were plotted as the heat flux density against the temperature difference $T_{p}-T_{f}$ for three selected distances: $0.06 \mathrm{~m} \mathrm{-} \mathrm{1/3} \mathrm{of} \mathrm{the}$ channel length from the inlet (a), $0.09 \mathrm{~m}-1 / 2$ of the channel length from the inlet (b), and $-0.12 \mathrm{~m}-1 / 3$ of the channel length from the outlet (c).

All curves were typical in shape. Spontaneous nucleation at boiling incipience caused a drop in the temperature of the heated surface, the phenomenon being known as "nucleation hysteresis" characteristic of highly wetting dielectric fluids (e.g. refrigerants). The bubbles act as internal heat sinks, absorbing a significant amount of energy transferred to the liquid [9, 11, 12]. The arrangement of points on the boiling curves shows the highest scatter and variability of the data obtained from 
experiments with the plate of $0.10 \mathrm{~mm}$ thickness. The highest temperature drops characteristic of boiling initiation are observed in boiling curves plotted for $0.10 \mathrm{~mm}$ and $0.65 \mathrm{~mm}$ thick plates. The boiling curves are close to parallel for the $0.45 \mathrm{~mm}$ and $0.65 \mathrm{~mm}$ thick plates. The relationships are shifted in the graph by the heat flux value of $20-30 \mathrm{~kW} \cdot \mathrm{m}^{-2}$ and temperature difference drops about $10 \mathrm{~K}$.
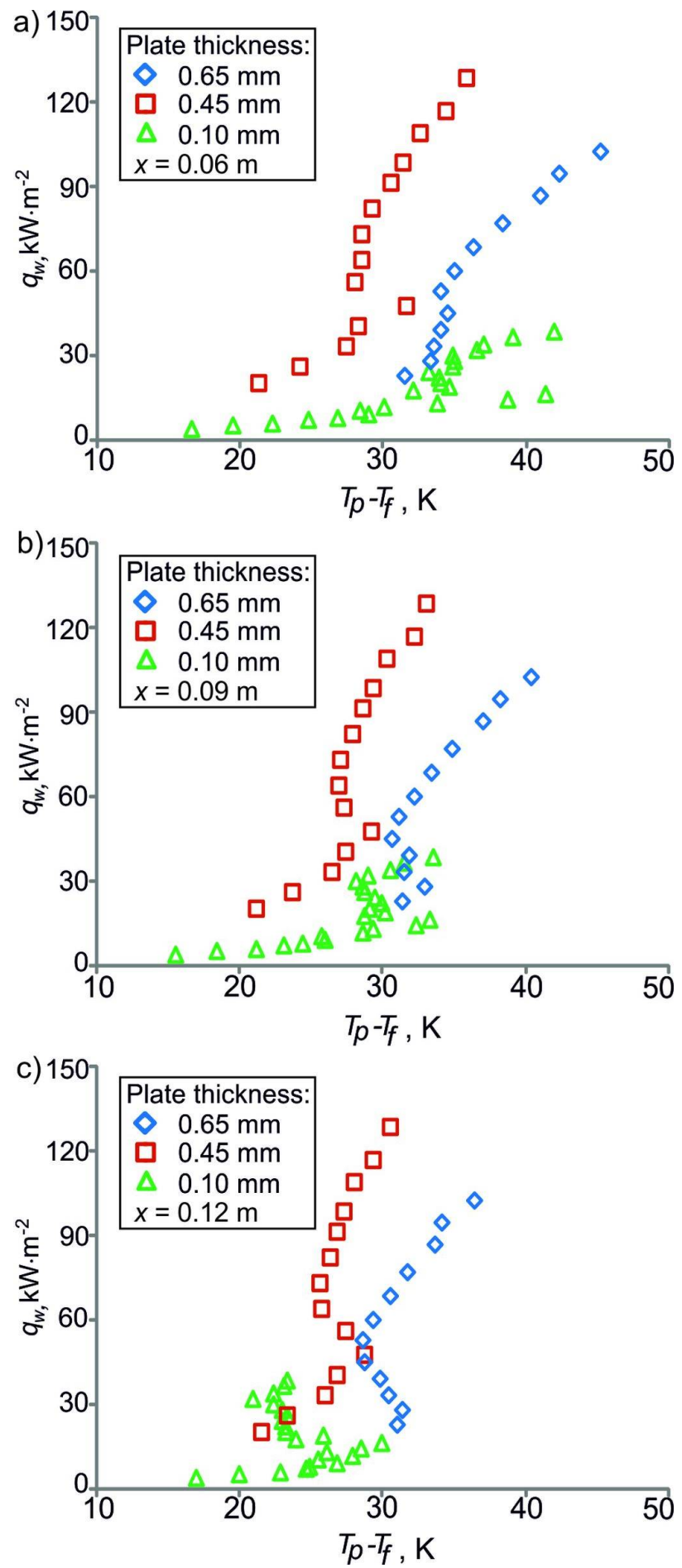

Fig. 8. Boiling curves generated for the three distances from the minichannel inlet: $0.06 \mathrm{~m}$ (a), $0.09 \mathrm{~m}$ (b) and $0.12 \mathrm{~m}$ (c) constructed as: $q_{w}$ vs. $T_{p}-T_{f}, T_{p}$ - heated plate temperature, $T_{f}$ - bulk fluid temperature.

\section{Conclusions}

This paper presents a comparison of the performance of three smooth heated surfaces with different thicknesses. Analysis was carried out on an experimental stand for flow boiling heat transfer. The test section with a rectangular minichannel, $1.7 \mathrm{~mm}$ deep, $16 \mathrm{~mm}$ wide and $180 \mathrm{~mm}$ long, oriented vertically. The heated element for the working fluid (FC-72) was designated as a Haynes-230 alloy plate: $0.10 \mathrm{~mm}$ and $0.45 \mathrm{~mm}$ thick or Hastelloy X alloy plate about $0.65 \mathrm{~mm}$ thick. Infrared thermography was used to measure the temperature of the outer plate surface.

The local values of the heat transfer coefficient were calculated using one-dimensional method in the subcooled boiling region at two heat fluxes supplied to the plates. The experimental results were presented as the relationship between the heat transfer coefficient vs the distance along the minichannel length and boiling curves.

In the tested boiling region was observed that the heat transfer coefficients were relatively low in comparison to those at the saturated boiling region. The highest local heat transfer coefficients were recorded for the surface of $0.10 \mathrm{~mm}$ thick heated plate at the outlet and $0.45 \mathrm{~mm}$ thick plate at the minichannel inlet.

The boiling curves were plotted as the heat flux density against the temperature difference $T_{p}-T_{f}$ for three selected distances from the minichannel inlet: $0.06 \mathrm{~m}$, $0.09 \mathrm{~m}$ and $0.12 \mathrm{~m}$. The highest temperature drops characteristic of boiling initiation were observed in boiling curves plotted for $0.10 \mathrm{~mm}$ and $0.65 \mathrm{~mm}$ thick plates.

\section{Acknowledgments}

The research reported herein was supported by a grant from the National Science Centre, Poland (No. DEC2016/23/N/ST8/01247).

\section{Nomenclature}

A surface area, $\mathrm{m}^{2}$

Co confinement number, -

$d_{h} \quad$ hydraulic diameter, $\mathrm{m}$

$G \quad$ mass flux, $\mathrm{kg} \cdot \mathrm{m}^{-2} \mathrm{~s}^{-1}$

$p_{\text {in }} \quad$ inlet pressure, $\mathrm{Pa}$

$q_{w}$ heat flux density, $\mathrm{W} \cdot \mathrm{m}^{-2}$

$\mathrm{Ra}$ arithmetic mean deviation of the roughness profile, $\mu \mathrm{m}$

$\mathrm{Sa}$ arithmetic mean height, $\mu \mathrm{m}$

$T$ temperature, $\mathrm{K}$

$x$ distance from the minichannel inlet, $\mathrm{m}$

$y$ the percentage value of heat transfer through the heated plate, $\%$

$z \quad$ the value of heat transfer through the heated plate, $\mathrm{W} \cdot \mathrm{m}^{-2} \cdot \mathrm{K}^{-1}$

Greek symbols

$\alpha \quad$ heat transfer coefficient, $\mathrm{W} \cdot \mathrm{m}^{-2} \cdot \mathrm{K}^{-1}$ 
$\Delta T_{\text {sub }} \quad$ inlet liquid subcooling, $\mathrm{K}$

$\delta \quad$ thickness, depth, $\mathrm{m}$

$\lambda$ thermal conductivity, $\mathrm{W} \cdot \mathrm{m}^{-1} \mathrm{~K}^{-1}$

Subscripts

$f \quad$ fluid

in at the inlet

$p \quad$ plate

\section{References}

1. R. Ali, B. Palm, M. H. Maqbool, J. Heat Transfer 133(8), 81501 (2011)

2. M.R. Sohel, R. Saidur, N.H. Hassan, M.M. Elias, S.S. Khaleduzzaman, I.M. Mahbubul, Int. Commun. Heat Mass Transf. 46, 85-91 (2013)

3. Shah, R. K., Classification of Heat Exchangers (Eds., Hemisphere Publishing Washington DC, 9-46, 1981)

4. S. G., Kandlikar, W. J. Grande, Heat Transf. Eng. 24(1), 3-17 (2003)

5. P. A. Kew, K. Cornwell, Appl. Therm. Eng. 17(8-10), 705-715 (1997).

6. B. Maciejewska, K. Strąk, M. Piasecka, Procedia Eng. 157, 82-88 (2016)

7. M. Piasecka, K. Strąk, B.Grabas, Arch. Metall. Mater. 62(4), 1983-1990 (2017)

8. M. Piasecka, Ann. Nucl. Energy 73, 282-293 (2014)

9. M. Piasecka, Int. J. Refrig. 56, 198-212 (2015)

10. M. Piasecka, Int. J. Heat Mass Transf. 81, 114-121 (2014)

11. M. Piasecka, B. Maciejewska, Exp. Therm. Fluid Sci. 68, 459-467 (2015)

12. K. Strąk, M. Piasecka, B. Maciejewska, Int. J. Heat Mass Transf. 117, 375-387 (2017)

13. W. Depczyński, J. Achiev. Mater. Manuf. Eng. 66(2), 67-72 (2014)

14. B. Grabas, Exp. Therm. Fluid Sci. 68, 499-508 (2015)

15. N. Radek, J. Konstanty, M. Scendo, Arch. Metall. Mater. 60, 2579-2584 (2015)

16. R. Pastuszko, R Kaniowski, EPJ Web Conf. 25, paper No. 02019 (2012)

17. R. Pastuszko, R Kaniowski, J. Phys. Conf. Ser. 745(3), paper No. 32137 (2016).

18. R. Pastuszko, EPJ Web Conf. 45, paper No. 01020 (2013)

19. R. Pastuszko, M. Piasecka, J. Phys. Conf. Ser. 395, paper No. 12137 (2012)

20. J. T. Cieśliński, Rev. Chem. Eng. 27(3-4), 179-190 (2011)

21. S. Błasiak, A. Zahorulko, Tribol. Int. 94, 126-137 (2016)

22. S. Błasiak, Int. J. Heat Mass Transf. 100, 78-88 (2016)

23. S. Błasiak, 2015, Int. J. Heat Mass Transf. 81, 90-102 (2015)

24. M. Piasecka, K. Strąk, B. Maciejewska, Heat Transf. Eng. 38(3), 332-346 (2017)

25. Calibration Certificate No. K1501035, Calibration Laboratory No. 2372, Accredited by Czech
Accreditation Institute under ČSN EN ISO/IEC 17025:2005

26. www.haynesintl.com/pdf/h3009.pdf

27. B. Maciejewska, M. Piasecka, Int. J. Heat Mass Transf. 107, 925-933 (2017)

28. S. Hozejowska, M. Piasecka, Heat Mass Transf. 50(8), 1053-1063 (2014)

29. B. Maciejewska, M. Piasecka, Heat Mass Transf. 53(4), 1211-1224 (2017)

30. S. Hożejowska, R. Kaniowski, M. E. Poniewski, Exp. Therm. Fluid Sci. 78, 18-29 (2016)

31. M. Piasecka, K. Strąk, Trans. Inst. Fuid-Flow Mach. 128, 97-118 (2015) 